\title{
Flow boiling instabilities of nitrogen in horizontal small diameter tube
}

\author{
Qiaoyu Zhang, and Jianjun Liu* \\ China Ship Development and Design Center, PR China 430000
}

\begin{abstract}
The flow boiling instability characteristics of nitrogen flow boiling in a horizontal small diameter tube were numerically studied, and a numerical model coupled with two phase flow boiling and system flow supplying was developed. With the steady state solution of the model, the flow boiling characteristic curve and flow supplying curve were obtained. The flow boiling characteristic curve was affected by the heat flux and inlet subcooling, meanwhile the flow supplying curve was affected by the total system pressure drop and friction feature of the flow supplying section. With the transient solution of the model, The dynamical response of pressure drop oscillations type (PDOs) instability of two phase flow were investigated, occurring region and trigging conditions were also obtained.
\end{abstract}

\section{Introduction}

The flow boiling heat transfer in small diameter channels is widely used in the electronics industry, aerospace and energy engineering fields, which has the advantages of high heat transfer coefficient and uniform heat transfer surface temperature, but also cause flow boiling instabilities [1]. Flow boiling instabilities may cause periodically oscillation of flow rate and pressure drop, which induce mechanical vibration and system control problems, lowering the safety of the whole system $[2,3]$.

The flow boiling instabilities mainly contain Lednegg instable flow (LED), density wave oscillations (DWOs) and pressure drop oscillations type (PDOs) instability. Kakac et al. [4] observed the PDOs and DWOs in R11 upflow boiling experiments. Stoddard et al. [5] found that increasing the heat flux and decreasing the pressure could result in the flow instability occurring in a higher mass flux region. Karsli and Comakli $[1,6]$ concluded that increase of inlet temperature will reduce the amplitude and period of the PODs and DWOs. Brutin and Tadrist [7,8] observed the flow instabilities at low Re. Wang et al. [9] found long-period and short-period instabilities in the experiments. Qi et al. [3] found long-period oscillations instabilities(50-65s) in liquid nitrogen flow boiling in 1.042 and $1.931 \mathrm{~mm}$ vertical tubes. Yu et al. [10] observed PDOs, DWOs appearing when the outlet quality was -0.001 to 0.012 in the experiments

It can be seen that the current researches are mainly focused on experimental studies, but there is no clear understanding on the mechanism of the flow boiling instabilities.

\footnotetext{
* Corresponding author: ztpica@163.com
} 
Therefore, a numerical model coupled flow boiling and flow supplying was established. Based on the model, the flow boiling characteristic curve and the flow supplying curve were studied. The PDOs instability was investigated on the aspects of dynamic response, occurrence region and triggering conditions.

\section{Numerical model}

As the two-phase flow instabilities essentially due to the mismatch between the flow supplying and the flow demanding. Therefore, it is necessary to establish a coupled numerical model for the flow supplying and the flow boiling in the pipe.

\subsection{The model of flow boiling in tube}

Due to the horizontal flow, the gravitational term (horizontal flow) in the momentum equation could be ignored, the governing equations including continuity equation, momentum equation and energy equation are as follows:

$$
\begin{gathered}
\frac{\partial \rho_{\mathrm{m}}}{\partial t}+\frac{\partial}{\partial z}\left(\rho_{\mathrm{m}} u_{\mathrm{m}}\right)=0 \\
\frac{\partial}{\partial t}\left(\rho_{\mathrm{m}} u_{\mathrm{m}}\right)+\frac{\partial}{\partial z}\left(\rho_{\mathrm{m}} u_{\mathrm{m}} u_{\mathrm{m}}\right)=-\frac{\partial p}{\partial z}+\left(-\frac{\partial p}{\partial z}\right)_{\mathrm{f}} \\
\frac{\partial}{\partial t}\left(\rho_{\mathrm{m}} H_{\mathrm{m}}\right)+\frac{\partial}{\partial z}\left(\rho_{\mathrm{m}} u_{\mathrm{m}} H_{\mathrm{m}}\right)=\frac{q \xi_{\mathrm{h}}}{A}
\end{gathered}
$$

Which, $\rho_{\mathrm{m}} / \mathrm{kg} \cdot \mathrm{m}^{-3}$ is the average density of the two phase flow, $\xi_{\mathrm{h}} / \mathrm{m}$ is the heat transfer perimeter, $A_{\mathrm{c}} / \mathrm{m}^{2}$ is the flow area. Therefore the mass flow in each cross section is given by:

$$
\frac{G}{u_{\mathrm{m}} \rho_{\mathrm{m}}}=\frac{G x}{u_{\mathrm{v}} \rho_{\mathrm{v}}}+\frac{G(1-x)}{u_{\mathrm{L}} \rho_{\mathrm{L}}}
$$

Homogeneous Flow Model was adopt, therefore, the average velocity and density are given by:

$$
\begin{aligned}
& u_{\mathrm{m}}=u_{\mathrm{V}}=u_{\mathrm{L}} \\
& \frac{1}{\rho_{\mathrm{m}}}=\frac{x}{\rho_{\mathrm{V}}}+\frac{1-x}{\rho_{\mathrm{L}}}
\end{aligned}
$$

$H_{\mathrm{m}}$ is the average enthalpy of the two phase flow, which could be calculated by the quality $x$ :

$$
H_{\mathrm{m}}=x H_{\mathrm{LV}}+H_{\mathrm{L}}
$$

Which $H_{\mathrm{LV}} / \mathrm{J} \cdot \mathrm{kg}^{-1}$ is latent heat of vaporization, $H_{\mathrm{L}} / \mathrm{J} \cdot \mathrm{kg}^{-1}$ is enthalpy of saturated liquid. $x$ is the equilibrium quality, $x<0$ means the subcooling, while $x>1$ means superheat conditions. And $(-\mathrm{d} p / \mathrm{d} z)_{\mathrm{f}}$ in momentum equation was calculated by the $\mathrm{C}$ correlation in [11] with Chisholm correlation.

\subsection{The numerical model of flow supplying}

The physical model shown in figure 1 mainly contains three parts, one reservoir having a constant pressure $p_{0}$, one surge tank and one test tube having a constant outlet pressure poutlet.

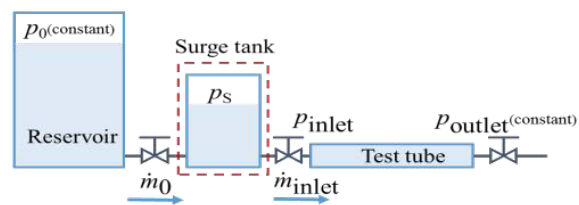

Fig. 1. Schematic of flow supplying with surge tank.

Since the fluid in the tube between the reservoir tank and surge tank, as well as the surge tank and test section is both subcooled liquid and having no heatleak for 
simplification, the continuity equation and energy equation could be ignored, the momentum equation of liquid-phase fluid for the two parts above are established as follows:

$$
\frac{\partial}{\partial t}\left(\rho_{\mathrm{L}} u_{\mathrm{L}}\right)=-\frac{\partial p}{\partial z}-\left(-\frac{\partial p}{\partial z}\right)_{\mathrm{f}}
$$

While the nitrogen inner the surge tank could obtained by the ideal gas law:

$$
p_{\mathrm{s}}=\frac{R_{\mathrm{g}} m_{\mathrm{v}} T_{\mathrm{V}}}{V_{\mathrm{v}}}
$$

Which $R_{\mathrm{g}}$ is the universal gas constant, $m_{\mathrm{V}}$ and $V_{\mathrm{V}}$ are the gas mass and volume inner the surge tank separately. The $(-\partial \mathrm{p} / \partial \mathrm{z})_{\mathrm{f}}$ in Eq.8 is the liquid friction pressure drop, which could be calculated by Blasius equation. The $p_{0}$ and $p_{\text {outlet }}$ shown in figure 1 are constant as boundary conditions.

\section{Study cases}

\subsection{Flow boiling characteristic curves and flow supplying curves}

The flow boiling characteristic curves and the flow supplying curves could obtained by the steady state solution of the numerical model. Figure 2 shows the relationship between the total pressure drop and mass flux in different heat flux conditions.

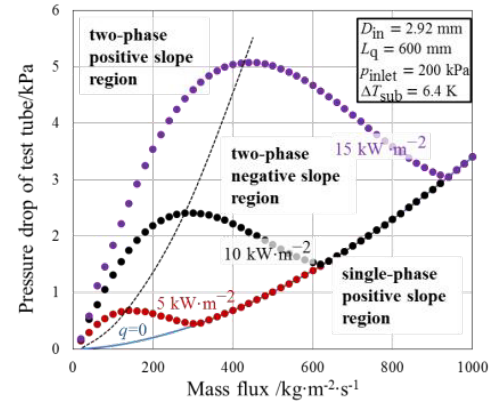

(a)Effect of heat flux

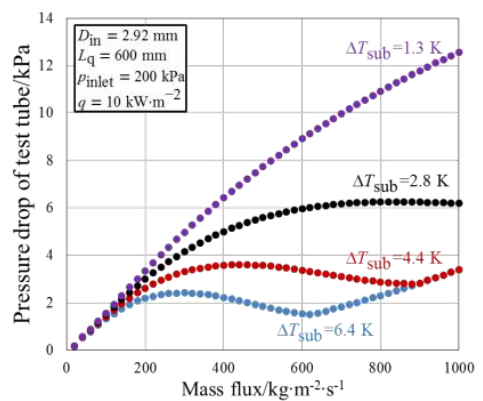

(b)Effect of mass flux

Fig. 2. Flow boiling characteristic curves.

It can be seen that the pressure drop is monotonically increase with mass flux when $q=0$, which is due to the fluid along the tube is liquid phase. When the heat flux $q=5,10,15$ $\mathrm{kW} \cdot \mathrm{m}^{-2}$ separately, the characteristic curve shows the "N" shape. This is because when the mass flow rate is high, the heat flux density is not enough to make the subcooled liquid nitrogen reach the two-phase state, so the tube is all liquid phase, so the pressure drop is monotonically decreased with mass flux decreased; with the mass flux decreases, the twophase state appears inner the tube, so the total pressure drop is increase with mass flux decrease; and when the mass flow rate continue to decline, the dryout condition appears in the tube, and the pressure drop decreased with the mass flux decrease. And the entire characteristic curve will be higher with the heat flux increase. When $q>0$, with the increase of mass flux, the characteristic curve is divided into three parts, which are separately singlephase positive slope region, two-phase negative slope region and two-phase positive slope region.

Figure 2(b) shows the characteristic curves under different inlet subcooling $\Delta T_{\text {sub }}$ conditions. It is found that with $\Delta T_{\text {sub }}$ decreases, the characteristic curve rises, resulting in the slope of the curve increase gradually, and finally the two-phase negative slope region disappears. 


\subsection{Flow supplying curve}

The flow supplying characteristic curves are similar to the external characteristic curves of the pump, which means when the system inlet and outlet pressures are constant $\left(p_{0}\right.$ and $p_{\text {outlet }}$ in figure 1$)$, the relationship between the pressure drop ( $\left.p_{\text {inlet }}-p_{\text {outlet }}\right)$ and the mass flow of the fluid. Define the dimensionless friction coefficient $f_{\mathrm{S}}$, which means the pressure drop friction characteristics of the tube:

$$
\Delta p=f_{\mathrm{s}} \frac{L_{0}}{D_{0}} \frac{0.3164}{\operatorname{Re}_{\mathrm{L}}^{0.25}} \frac{G}{2 \rho}
$$

Which $L_{0}=1 \mathrm{~m}, D_{0}=3 \mathrm{~mm}$ are the standard tube length and tube diameter separately.

Figure 3 shows the flow supplying curves. It can be seen the characteristic curve increases with the total pressure drop increases (figure 3(a)), and the curves become steeper as the friction characteristics become larger (figure 3(b)).

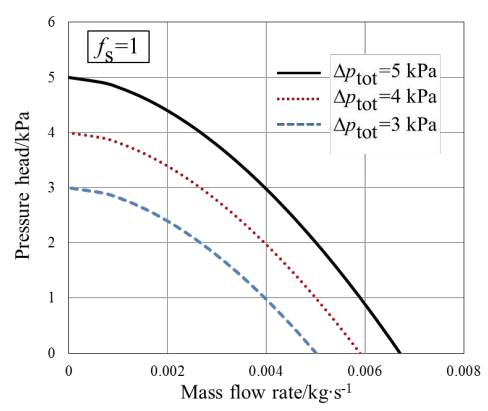

(a)Effect of the total pressure drop

Fig. 3. Flow supplying curves.

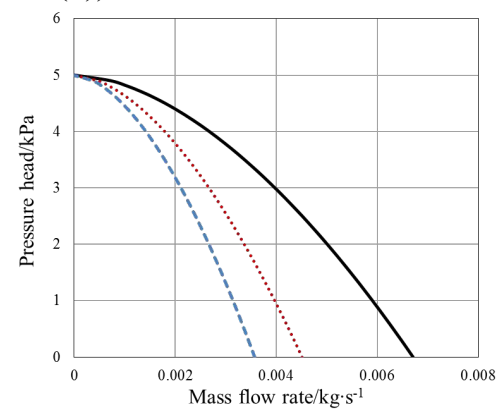

(b)Effect of the pressure drop friction

\subsection{Dynamic response of the three types of instabilities}

The flow chart of dynamic response calculation was shown in figure 4, the initial steadystate results are obtained firstly. Then, one perturbation was added, after which the transient calculation is operated to obtain the dynamic response of pressure, flow rate and temperature results. In the calculation, the added perturbation is the change of the mass flux at the test tube inlet $\Delta G / \Delta t$, afterwards the transient calculations could be operated by the numerical model automatically.

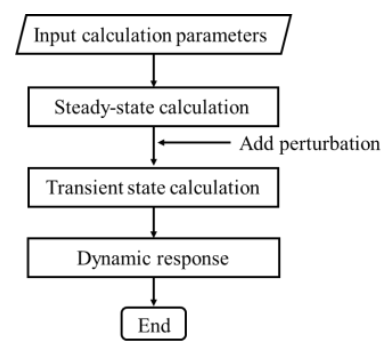

Fig. 4. Flow chart of dynamic response calculation.

Pressure drop oscillations (PDOs) typically appears in the conditions having surge tank upstream of the test tube, which always induce flow excursion and intense oscillations of pressure, mass flux and surface temperature. The dynamic response of PDOs are shown in figure 5 , and the calculation parameters were shown in table 1.

Table 1. Calculation paremeters and adding perturbation.

\begin{tabular}{|l|l|l|l|l|l|}
\hline$D / \mathrm{mm}$ & $q / \mathrm{kW} \cdot \mathrm{m}^{-2}$ & $P_{\text {inlet }} / \mathrm{kPa}$ & $\Delta T_{\text {sub }} / \mathrm{K}$ & $G_{\text {inlet }} / \mathrm{kg} \cdot \mathrm{m}^{-2} \cdot \mathrm{s}^{-1}$ & $\Delta G / \Delta t\left(\mathrm{~kg} \cdot \mathrm{m}^{-2} \cdot \mathrm{s}^{-2}\right)$ \\
\hline 2.92 & 10 & 200 & 6.4 & 500 & \pm 0.1 \\
\hline
\end{tabular}




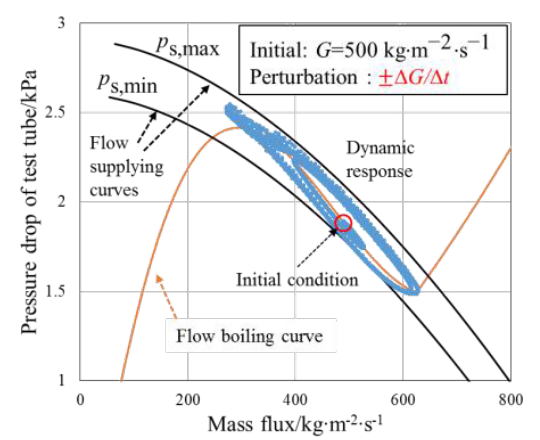

(a) Characteristic curves and dynamic response

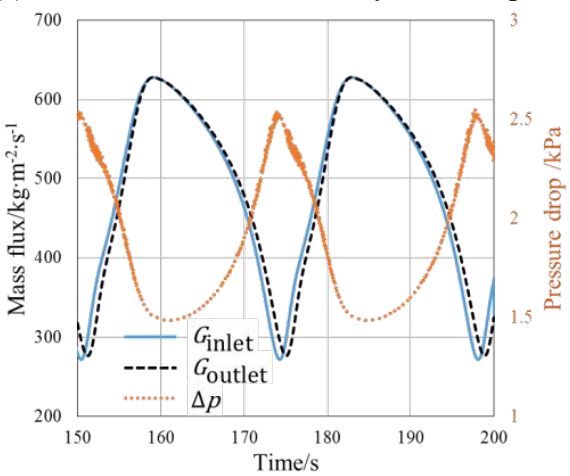

(c)Mass flux and pressure drop change with time

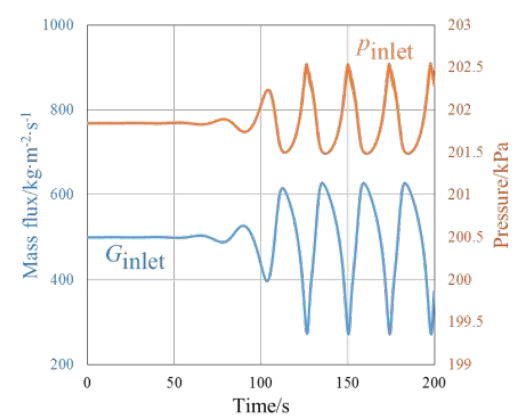

(b)Mass flux and pressure at inlet changes with time

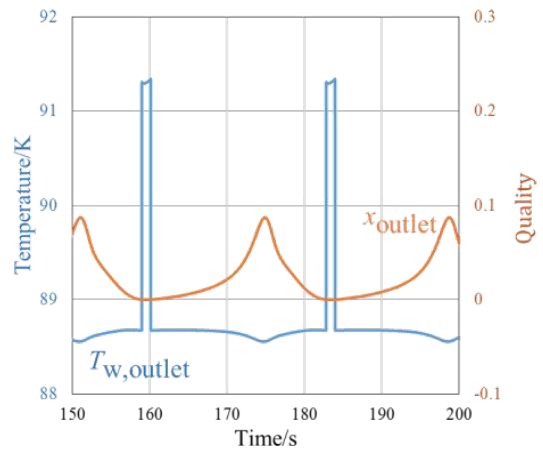

(d)Temperature of surface and quality at outlet change with time

Fig. 5. Pressure drop osillations (PDOs) type instability $\Delta T_{\text {sub }}=6.4 \mathrm{~K}$.

It can be seen from the figure 5 (a) that the flow supplying characteristic curve are not unique, and the curve of the maximum pressure and the minimum pressure of the surge tank were given in the figure. The dynamic response is in the region between the two characteristic curves, the working conditions change periodically with the flow excursion appears. Figure 5 (b) shows the mass flux and pressure of the tube inlet changes with time, it can be seen that although the perturbation is added at time 0 , the system is in a "false" stable state during about $80 \mathrm{~s}$, and then the mass flux and pressure started having a fixed period of oscillations, and maintained a stable phase-difference. Figure 5 (c) shows the mass flux and pressure differential having a phase-difference. When the mass flux is maximum, the pressure drop is minimum, and at this time the fluid inner the whole tube is liquid state, so the phase-difference between inlet and outlet mass flow rate disappears. Figure 5(d) shows that due to the flow condition periodically goes into the full liquid region, the heat transfer is changed from the nucleate boiling to single-phase convection, so the heat transfer coefficient decreases dramatically, and the surface temperature having a huge temperature jump.

From the calculation of the numerical model, the PDOs generally occurs in the twophase negative slope region, and requires two conditions: (1) the system has a surge tank, in which the pressure changes periodically, (2) The slope of the flow supplying characteristic curve is greater than the flow boiling characteristic curves. When the PDOs appears, the surface temperature may have a wide range of fluctuations, because the fluid periodically goes into the single-phase liquid region, which change the heat transfer mechanism, leading to the changes of the heat transfer coefficient, resulting in a periodically wild change of wall temperature. 


\section{Conclusions}

The flow boiling of liquid nitrogen in a horizontal small diameter tube was numerical studied in this paper. The numerical model coupled with flow boiling in tubes and flow supplying was developed. Based on the steady-state solutions of the model, the characteristic curves of flow boiling and flow supplying were studied respectively, which the former is affected by the heat flux and inlet subcooling, while the latter is affected by the total pressure drop and the friction characteristics of the supplying tube. Based on the transient solutions, the characteristic mechanism of the pressure drop oscillations (PDOs) was studied. The dynamic response, occurrence region and trigger conditions were obtained.

\section{References}

1. Karsli S, Yilmaz M, Comakli O. The effect of internal surface modification on flow instabilities in forced convection boiling in a horizontal tube[J]. International Journal of Heat \& Fluid Flow, 2002, 23 (6): 776-791.

2. Kakaç S, Cao L. Analysis of convective two-phase flow instabilities in vertical and horizontal in-tube boiling systems[J]. International Journal of Heat \& Mass Transfer, 2009, 52 (17-18): 3984-3993.

3. Qi SL, Zhang P, Wang RZ, et al. Flow boiling of liquid nitrogen in micro-tubes: Part I - The onset of nucleate boiling, two-phase flow instability and two-phase flow pressure drop[J]. International Journal of Heat and Mass Transfer, 2007, 50 (25-26): 4999-5016.

4. Kakaç S, Veziroğlu TN, Padki MM, et al. Investigation of thermal instabilities in a forced convection upward boiling system[J]. Experimental Thermal \& Fluid Science, 1990, 3 (2): 191-201.

5. Stoddard RM, Blasick AM, Ghiaasiaan SM, et al. Onset of flow instability and critical heat flux in thin horizontal annuli[J]. Experimental Thermal \& Fluid Science, 2002, 26 (1): $1-14$

6. Çomaklı Ö, Karslı S, Yılmaz M. Experimental investigation of two phase flow instabilities in a horizontal in-tube boiling system[J]. Energy Conversion \& Management, 2002, 43 (2): 249-268.

7. Brutin D, Tadrist L. Pressure drop and heat transfer analysis of flow boiling in a minichannel: influence of the inlet condition on two-phase flow stability[J]. International Journal of Heat \& Mass Transfer, 2004, 47 (10-11): 2365-2377.

8. Brutin D, Topin F, Tadrist L. Experimental study of unsteady convective boiling in heated minichannels[J]. International Journal of Heat \& Mass Transfer, 2003, 46 (16): 2957-2965.

9. Wang $\mathrm{G}$, Cheng $\mathrm{P}, \mathrm{Wu} \mathrm{H}$. Unstable and stable flow boiling in parallel microchannels and in a single microchannel[J]. International Journal of Heat \& Mass Transfer, 2007, 50 (21-22): 4297-4310.

10. Yu Z, Yuan H, Chen C, et al. Two-phase flow instabilities of forced circulation at low pressure in a rectangular mini-channel[J]. International Journal of Heat and Mass Transfer, 2016, 98: 438-447.

11. Chen X, Chen S, Chen J, et al. Two-phase flow boiling frictional pressure drop of liquid nitrogen in horizontal circular mini-tubes: Experimental investigation and comparison with correlations[J]. Cryogenics, 2017, 83: 85-94. 